\title{
Perception of Environmental Risks and Behavioral Changes during Pregnancy: A Cross-Sectional Study of French Postpartum Women
}

\author{
Raphaëlle Teysseire ${ }^{1,2, * \mathbb{C}}$, Marion Lecourt ${ }^{3}$, Jim Canet ${ }^{4}{ }^{\mathbb{D}}$, Guyguy Manangama ${ }^{1,2,4}$, \\ Loïc Sentilhes ${ }^{1,5}$ and Fleur Delva ${ }^{1,2,4}$ (i) \\ 1 Environmental Health Platform Dedicated to Reproduction, ARTEMIS Center, 33076 Bordeaux, France; \\ guyguy.manangama@chu-bordeaux.fr (G.M.); loic.sentilhes@chu-bordeaux.fr (L.S.); \\ fleur.delva@chu-bordeaux.fr (F.D.) \\ 2 Department of Occupational Medicine, Bordeaux Hospital, Bordeaux, 33076 Bordeaux, France \\ 3 Midwifery School, 33076 Bordeaux, France; lecourtmarion00@gmail.com \\ 4 Bordeaux Population Health Research Center, Inserm UMR1219-EPICENE, University of Bordeaux, \\ 33076 Bordeaux, France; jim.canet@u-bordeaux.fr \\ 5 Department of Obstetrics and Gynecology, Bordeaux Hospital, Bordeaux, 33076 Bordeaux, France \\ * Correspondence: raphaelle.teysseire@chu-bordeaux.fr; Tel.: +33-(5)-57-82-16-27
}

Received: 11 January 2019; Accepted: 7 February 2019; Published: 16 February 2019

\begin{abstract}
Limiting exposure to environmental hazards during preconception and pregnancy is essential for preventing adverse pregnancy outcomes or developmental defects in offspring. However, the perception of environmental risk and the behavioral changes of women planning or having a pregnancy have rarely been investigated, except for a few risk factors. We thus performed a cross-sectional study of French postpartum women hospitalized in the Bordeaux University Hospital in 2017 by proposing a self-administrated survey. The main objective was to assess their level of awareness concerning a large panel of environmental hazards and modifications in their behavior during pregnancy in occupational and household environments. Among the 121 respondents, most identified the environment as a major factor for a healthy pregnancy but recognized a lack of knowledge regarding environmental risk factors. The internet, television, and magazines were their main sources of information. Most women modified some of their practices at work or home. These measures were rarely implemented in consultation with a health practitioner, which raises concerns about the relevance of the adjustments made. Our findings highlight the need to improve the quality of information available to women and to help them implement preventive measures in consultation with physicians.
\end{abstract}

Keywords: environmental health; pregnancy; prenatal care; prevention; behavioral changes; risk perception; occupational health; health knowledge; attitudes; practice

\section{Introduction}

Environmental exposure to reproductive hazards during the periods of conception, pregnancy, and breastfeeding can lead to adverse pregnancy outcomes or developmental defects in offspring. The lifestyle of women before and during pregnancy is a crucial component of fetal and child development. Several studies have shown that prenatal consumption of tobacco, alcohol, or cannabis is associated with reduced birth weight and preterm delivery, as well as behavioral and cognitive deficits during childhood [1]. Recent epidemiological studies have raised concerns about prenatal exposure to substances found in daily products, such as brominated flame retardants, phthalates, and pyrethroids, which may cause adverse cognitive and behavioral outcomes in offspring [2]. Finally, several activities, 
such as home renovation, can lead to exposure to lead or organic solvents, both associated with adverse pregnancy outcomes or impairment of postnatal development [3]. Moreover, occupational exposure can also adversely affect reproductive health. For example, studies have shown that parental employment in agriculture may contribute to stillbirth and increase the risk of congenital malformations and organ-system defects in their offspring [4,5]. The nursing profession, or work as a hairdresser or cosmetologist have been associated with several adverse pregnancy outcomes [6-10].

Consequently, preventing exposure to environmental hazards is a priority as early as the preconception period, as recommended by the International Federation of Gynecology and Obstetrics in 2015 [11].

Several appropriate actions have already been implemented in both occupational and non-occupational settings. Preconception health care information to alert women about environmental risks during pregnancy is provided in many countries [12]. The dissemination of such information can take the form of individual counselling, group health education, mass media campaigns, or websites $[12,13]$. In the workplace, statutory measures have been implemented to prevent pregnant or nursing women from performing dangerous or unhealthy tasks in 111 countries throughout the world [14].

Yet, despite the existence of such preventive measures, it is unclear whether women planning or having a pregnancy are truly informed about the environmental risks to reproductive health and whether they subsequently change their behavior concerning their work practices or household habits, with possible help from health practitioners.

Although many existing studies have focused on knowledge and behavioral changes concerning ingested substances, such as alcohol, tobacco smoke, recreational drugs, or pharmaceuticals (especially folic acid and vaccines), only a few have dealt with other harmful environmental substances [15]. Two studies conducted in France showed that pregnant women do not receive sufficient information concerning the potential sources of exposure to five reprotoxic agents and endocrine disrupters $[16,17]$. However, these studies focused on targeted risks factors and did not investigate actual behavioral changes during pregnancy.

In the workplace, one study carried out in France showed that, although exposure to occupational risk is frequent among pregnant workers, prevention is still very limited [18]. This study did not investigate the women's perceptions concerning occupational risks or personal behavioral changes.

There are no studies that have jointly investigated occupational and non-occupational environments. However, it would be informative to simultaneously observe occupational and non-occupational environments, as they both contribute to the global exposure of women to reproductive hazards, with the proportion varying from case to case.

The first objective of our study was to evaluate women's knowledge about the environmental exposures that could interfere with the proper course of pregnancy. The second objective was to assess the behavioral changes they established in their private and professional lives.

\section{Materials and Methods}

Our study was a cross-sectional survey of postpartum women hospitalized in the Department of Obstetrics and Gynecology of the Bordeaux University Hospital. This department contains a maternity ward that specializes in handling high-risk pregnancies and a neighborhood maternity for normal pregnancies.

Our study included women hospitalized in the postnatal care and delivery unit during two periods (from 16 October 2017 to 26 October 2017 and 27 November 2017 to 7 December 2017) who gave birth to a healthy child. Indeed, the main preoccupation was to avoid generating anxiety among patients. We chose to exclude women who were currently pregnant, women with adverse pregnancy outcomes (such as preeclampsia, preterm delivery, intrauterine growth restriction, congenital malformation ... ), and those with language barriers or reading difficulties that prevented them from fully understanding the survey. 
We developed an anonymous self-administrated survey composed of 30 items consisting of closed questions (available upon request from the authors). The survey was structured in four parts. Part 1 requested general information about the participants' socio-demographic status and data concerning the pregnancy. Part 2 examined their perception of occupational risks to pregnancy and their attitudes at the workplace. In part 3, we asked them to rank 14 preventive measures that could be implemented at home in order of priority from 1 to 5 and asked them about behavioral changes they made in their personal life. Part 4 explored their information sources about the environment and pregnancy.

The survey was distributed to the eligible women by a single trained midwife with a letter explaining the framework and purpose of the study. Help was offered to women who had difficulties understanding or answering the questions. Women who participated could return the survey to the perinatal health providers during their hospitalization.

The data were entered using Epi Info 7 software [19]. The same software was used for the analysis. Numeric variables are presented as means and medians and categorical variables as headcounts and proportions.

We then performed a comparison of the responses using the chi-squared test or Fisher's exact test for various groups according to the following parameters: The education level defined by the Standard Classification of Education (ISCED) 2011 level (tertiary education corresponding to level 5 or more) [20], the declared number of pregnancies, and the possibility of exposure to environmental risk factors at work. Environmental risk factors on reproduction have been identified according to a method presented in a previous work [21]. We grouped them into four classes: Physical demands, reprotoxic agents, biological agents, and radiation. Following this, three experts categorized women in none or several categories of exposure on the basis of their profession and the company's activity. Significance was defined as $p<0.05$. This study was declared to the French CNIL (Commission nationale de l'informatique et des libertés, number $\mathrm{N}^{\circ} 2109748$ ).

\section{Results}

\subsection{Characteristics of the Study Population}

In total, 121 hospitalized women responded to the survey (Figure 1).

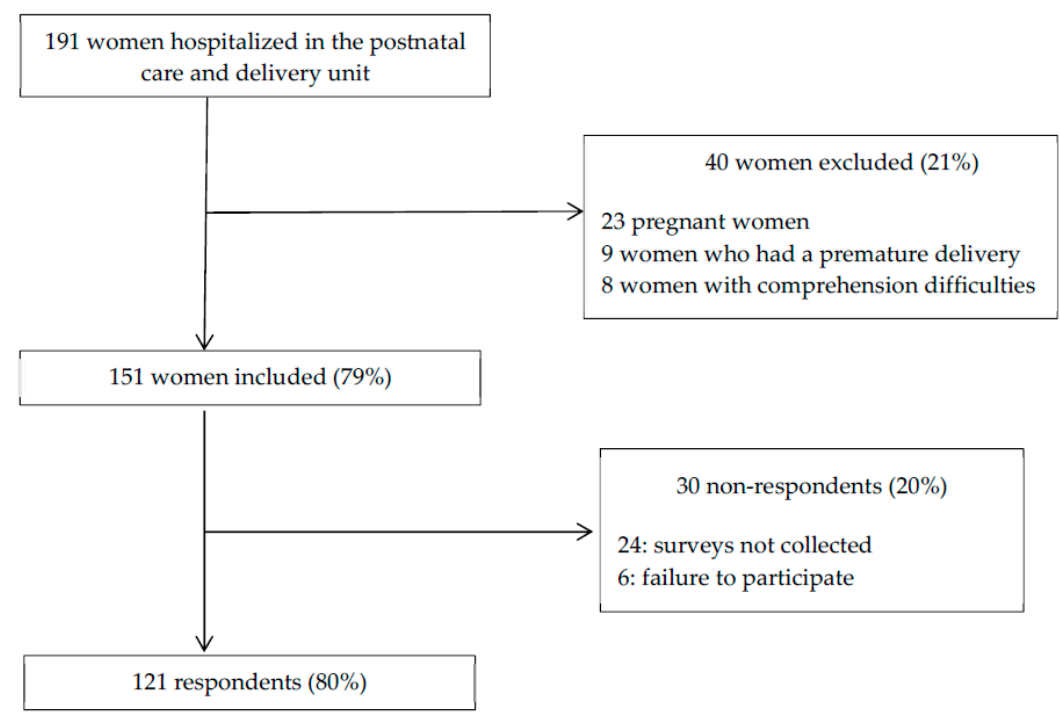

Figure 1. Inclusion and participation rate of women hospitalized in the postnatal care and delivery unit at the time of the study.

Table 1 presents the main characteristics of our study population according to their work status during the pregnancy. Most women $(n=90,74 \%)$ declared to have worked during this period. Workers 
tended to be older and had a higher education level than unemployed women $(p=0.02)$. In the total population, most women lived with a partner $(92 \%)$, had planned the pregnancy $(75 \%)$, and were aware of their pregnancy as soon as the first month $(92 \%)$.

Table 1. Description of survey respondents $(n=121)$.

\begin{tabular}{|c|c|c|c|c|c|c|c|}
\hline & \multicolumn{2}{|c|}{ Total $(n=121)$} & \multicolumn{2}{|c|}{ Workers $(n=90)$} & \multicolumn{2}{|c|}{ Unemployed $(n=31)$} & \multirow{2}{*}{$p$-Value * } \\
\hline & $n$ & $\%$ & $n$ & $\%$ & $n$ & $\%$ & \\
\hline Age & & & & & & & 0.03 \\
\hline$<25$ & 15 & 12.4 & 7 & 7.8 & 8 & 25.8 & \\
\hline $25-35$ & 69 & 57.0 & 52 & 57.8 & 17 & 54.9 & \\
\hline$>35$ & 37 & 30.6 & 31 & 34.4 & 6 & 19.3 & \\
\hline Education level & & & & & & & 0.02 \\
\hline Level 0 to 4 & 52 & 43.0 & 33 & 36.7 & 19 & 61.3 & \\
\hline Level 5 to 8 & 69 & 57.0 & 57 & 63.3 & 12 & 38.7 & \\
\hline Living with a partner ${ }^{1}$ & 111 & 94.1 & 83 & 95.4 & 28 & 90.3 & 1 \\
\hline Planned pregnancy ${ }^{2}$ & 91 & 75.2 & 70 & 77.8 & 21 & 67.7 & 0.28 \\
\hline Primigravid women & 37 & 30.6 & 26 & 28.9 & 11 & 35.5 & 0.49 \\
\hline Knowledge of pregnancy ${ }^{3}$ & & & & & & & 0.34 \\
\hline $0-1$ month & 110 & 91.7 & 82 & 92.1 & 28 & 90.3 & \\
\hline $1-3$ months & 9 & 7.5 & 7 & 7.9 & 2 & 6.5 & \\
\hline 3-4 months & 1 & 0.8 & 0 & 0 & 1 & 3.2 & \\
\hline
\end{tabular}

The professions of women who worked during pregnancy are presented in order of frequency in Table 2, sorted according to the major groups defined by the International Standard Classification of Occupations (ISCO-08) [22].

Table 2. Professions of women who worked during their pregnancy $(n=90)$.

\begin{tabular}{ccc}
\hline Group of Profession & $\boldsymbol{n}(\boldsymbol{n = 9 0 )}$ & $\mathbf{\%}$ \\
\hline Technicians and associate professionals & 30 & 33.3 \\
Professionals & 21 & 23.3 \\
Service and sales workers & 11 & 12.2 \\
Managers & 10 & 11.1 \\
Clerical support workers & 7 & 7.8 \\
Elementary occupations & 6 & 6.7 \\
Skilled agricultural, forestry, and fishery workers & 2 & 2.2 \\
\hline Total $^{1}{ }^{1}$ Three missing values. & 87 & 96.6
\end{tabular}

\subsection{Perception of Environmental Risks and Behavioral Changes at the Workplace}

The nature of the job and the main activity of the company allowed us to categorize one woman $(1.1 \%)$ as potentially exposed to ionizing radiation and nine $(10.0 \%)$ to biological risk factors for reproduction, $20(22.2 \%)$ as possibly exposed to reprotoxic agents, and $33(36.7 \%)$ as potentially exposed to an accumulation of physical demands and/or organizational constraints.

There was a significant association between the level of education and exposure to occupational reproductive risk factors: Women with a high degree of education were less exposed at work than women with a lower level of education $(p<0.001)$.

Table 3 presents the behaviors and actions implemented by subjects at the workplace. Globally, $46 \%$ of the respondents $(n=39)$ declared their pregnancy to the employer during the 
first trimester of pregnancy and 55\% stopped working during the last trimester. Only $10 \%(n=8)$ consulted an occupational physician during the pregnancy. Nevertheless, their workstation was adapted during this period, $71 \%$ by themselves $(n=60)$ and $40 \%$ with the assistance of their employer $(n=34)$. Women considered to be exposed tended to be more inclined to establish preventive measures and stopped working earlier than unexposed workers, but the difference was not statistically significant. However, women with a lower level of education more often changed their working practices $(p=0.04)$.

Table 3. Actions implemented in the workplace during the pregnancy $(n=90)$.

\begin{tabular}{|c|c|c|c|c|c|c|c|}
\hline & \multicolumn{2}{|c|}{$\begin{array}{c}\text { Total } \\
(n=90)\end{array}$} & \multicolumn{2}{|c|}{$\begin{array}{l}\text { Exposed } \\
(n=42)\end{array}$} & \multicolumn{2}{|c|}{$\begin{array}{l}\text { Unexposed } \\
\quad(n=48)\end{array}$} & \multirow[t]{2}{*}{$p$-Value * } \\
\hline & $n$ & $\%$ & $n$ & $\%$ & $n$ & $\%$ & \\
\hline $\begin{array}{l}\text { Pregnancy declaration date to } \\
\text { the employer }{ }^{1}\end{array}$ & & & & & & & 0.75 \\
\hline $0-3$ months & 39 & 46.4 & 19 & 51.4 & 20 & 42.6 & \\
\hline 3-4 months & 30 & 35.7 & 13 & 35.1 & 17 & 36.2 & \\
\hline 4-6 months & 13 & 15.5 & 4 & 10.8 & 9 & 19.1 & \\
\hline 6-9 months & 2 & 2.4 & 1 & 2.7 & 1 & 2.1 & \\
\hline Cessation of work $^{2}$ & & & & & & & 0.27 \\
\hline 0-3 months & 5 & 6.0 & 1 & 2.6 & 4 & 8.7 & \\
\hline 3-4 months & 6 & 7.1 & 4 & 10.5 & 2 & 4.3 & \\
\hline $4-6$ months & 27 & 32.1 & 15 & 39.5 & 12 & 26.1 & \\
\hline 6-9 months & 46 & 54.8 & 18 & 47.4 & 28 & 60.9 & \\
\hline $\begin{array}{l}\text { Behavioral change at the work } \\
\text { station by women }{ }^{2}\end{array}$ & 60 & 71.4 & 30 & 78.9 & 30 & 65.2 & 0.17 \\
\hline $\begin{array}{l}\text { Change made by the employer at } \\
\text { the work station }{ }^{3}\end{array}$ & 34 & 40.5 & 13 & 34.2 & 21 & 45.7 & 0.29 \\
\hline $\begin{array}{l}\text { No change made at the } \\
\text { workstation }\end{array}$ & 17 & 18.9 & 5 & 11.9 & 12 & 25 & 0.11 \\
\hline $\begin{array}{l}\text { Medical visit with the } \\
\text { occupational health physician } 4\end{array}$ & 8 & 10.3 & 3 & 9.4 & 5 & 10.9 & 1 \\
\hline
\end{tabular}

${ }^{1}$ Six missing values or women without employer (five exposed and one unexposed subjects); ${ }^{2}$ six missing values or women without employer (four exposed and two unexposed subjects); ${ }^{3}$ six missing values (four exposed subjects and two unexposed subjects); ${ }^{4} 12$ missing values (ten exposed subjects and two unexposed subjects). ${ }^{*}$ Chi-squared test or Fisher's exact test.

Figure 2 shows the behavioral changes initiated by the women themselves or their employers in the occupational environment. The most common measures implemented were adaptation of working hours and a reduction in biomechanical demands.

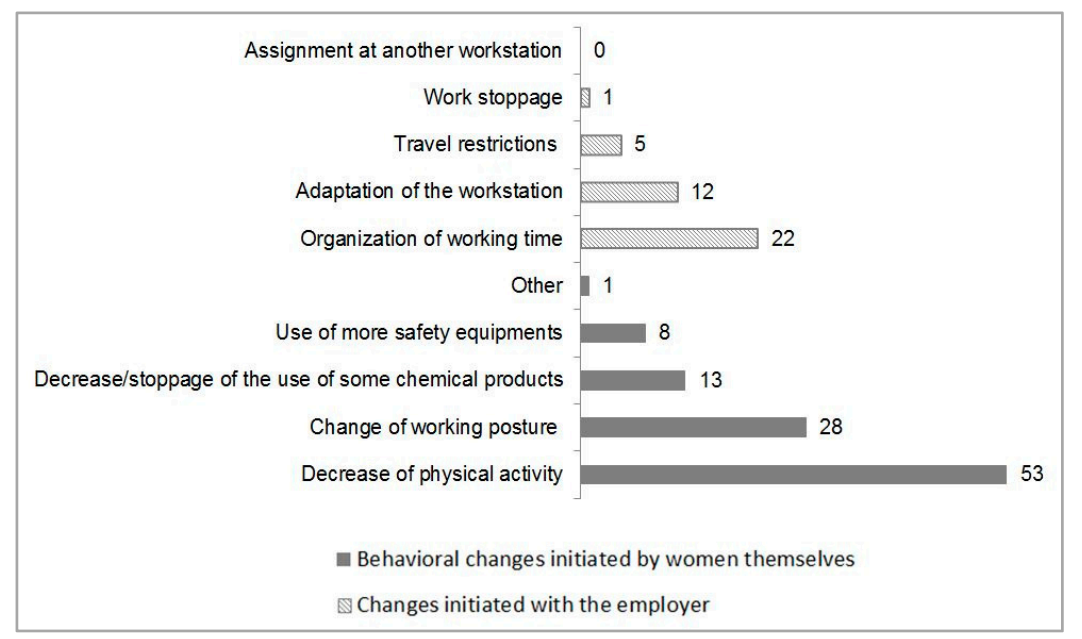

Figure 2. Behavioral changes initiated by women themselves or by their employers $(n=90)$. 
There were no significant differences in behavior or the establishment of preventive measures at the workplace according to the women's level of education or number of pregnancies.

\subsection{Perceptions of Environmental Risks in the Non-Occupational Environment}

Almost all women $(91 \%, n=107)$ considered the environment as a predominant factor to guarantee a healthy pregnancy. The answer was widely influenced by the level of education, as $99 \%(n=68)$ of the more highly educated subjects responded favorably versus $80 \%$ among the women with a lower level of education $(p=0.001)$.

Figure 3 shows the five actions chosen by the subjects among 14 propositions to establish a healthy environment at home during pregnancy. We represented proportions of answers by order of priority (first choice or further selection).

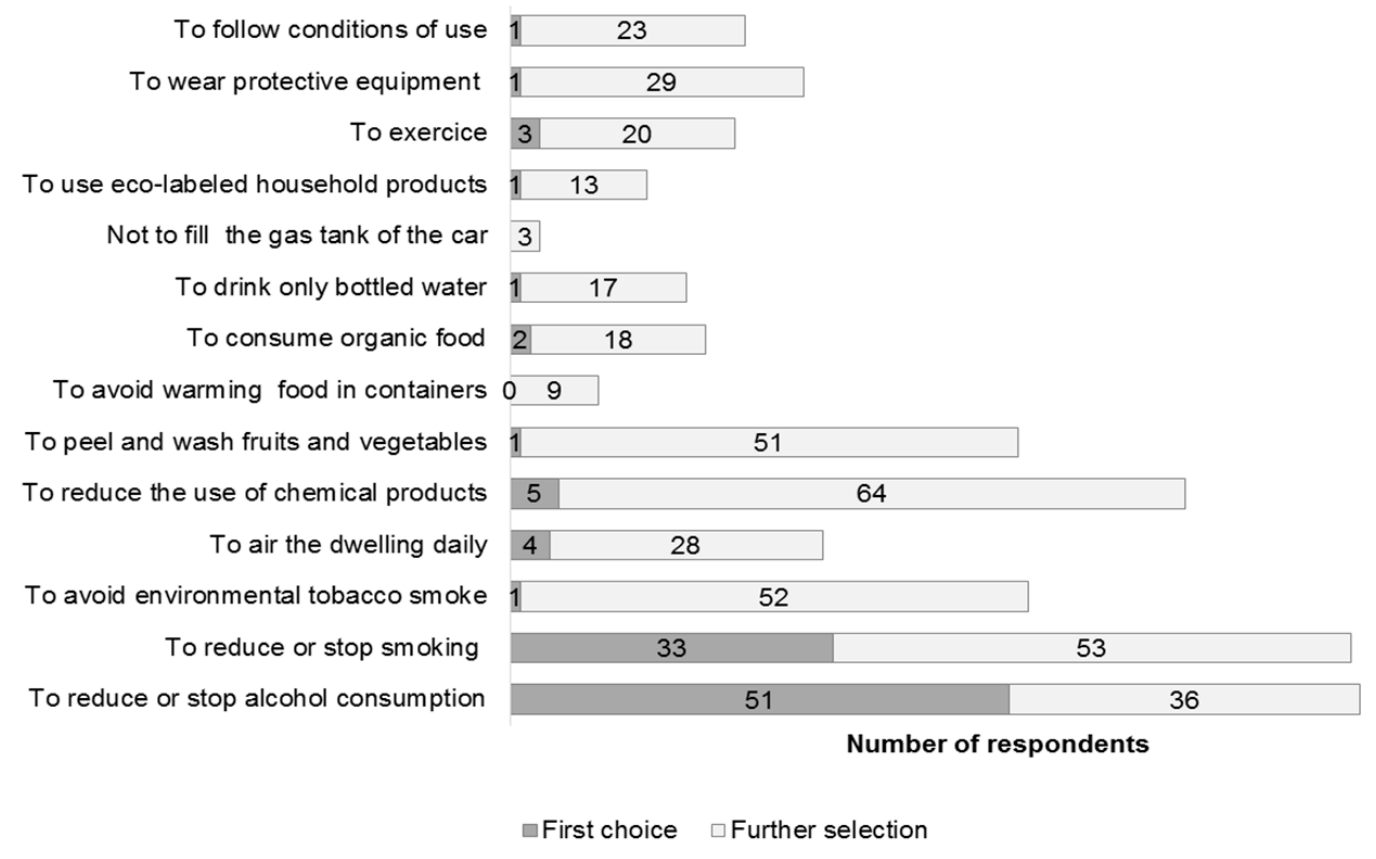

Figure 3. High priority actions chosen by women to improve their health during pregnancy $(n=121)$.

The most frequent preventive actions regarding lifestyle identified by $70 \%$ of women $(n=85)$ concerned limiting exposure to tobacco and alcohol. Answers to more specific questions concerning the potential link between alcohol and tobacco consumption and pregnancy issues are presented in Table 4 according to the subjects' level of education. No respondents considered alcohol and tobacco consumption to be safe during pregnancy. Many women considered such consumption not only harmful during pregnancy but also during the preconception period.

Thus, $56 \%(n=29)$ of women with a lower level of education and $80 \%(n=55)$ with a higher level of education indicated reducing or stopping tobacco and alcohol consumption as the most important actions to guarantee a safe pregnancy.

Changes in the consumption of alcohol were more frequently mentioned than for tobacco, especially among women with a higher level of education. They considered stopping alcohol consumption as essential to guarantying a healthy pregnancy $(p=0.05)$, some as even the most important action $(p=0.016)$.

\subsection{Behavioral Changes in the Non-Occupational Environment}

Behavioral changes in lifestyle concerning tobacco and alcohol consumption are presented in Table 5 . In our study population, $18 \%$ of women $(n=21)$ smoked before pregnancy, with a higher proportion among women with a lower education level $(p=0.003)$. All smokers declared to have 
stopped or reduced their tobacco consumption at the beginning of the pregnancy. More women with a high level of education stopped smoking $(n=4,64 \%)$, with no statistical difference. Ten women declared to have consumed alcohol daily before pregnancy and no subject declared to have consumed alcohol daily during pregnancy.

Table 4. Women's knowledge about alcohol and tobacco consumption during pregnancy.

\begin{tabular}{|c|c|c|c|c|c|c|c|}
\hline & \multicolumn{2}{|c|}{$\begin{array}{c}\text { Total } \\
(n=121)\end{array}$} & \multicolumn{2}{|c|}{$\begin{array}{c}\text { Level } 0 \text { to } 4 \text { of } \\
\text { Qualification } \\
\quad(n=52)\end{array}$} & \multicolumn{2}{|c|}{$\begin{array}{c}\text { Level } 5 \text { to } 8 \text { of } \\
\text { Qualification } \\
\quad(n=69)\end{array}$} & \multirow[t]{2}{*}{$p$-Value } \\
\hline & $n$ & $\%$ & $n$ & $\%$ & $n$ & $\%$ & \\
\hline Period of alcohol consumption dangerous for pregnancy ${ }^{1}$ & & & & & & & 0.78 \\
\hline As soon as the period of conception & 28 & 23.7 & 11 & 22.4 & 17 & 24.6 & \\
\hline As soon as the beginning of pregnancy & 90 & 76.3 & 38 & 77.6 & 52 & 75.4 & \\
\hline As soon as the beginning of pregnancy & 63 & 53.8 & 29 & 60.4 & 34 & 49.3 & \\
\hline $\begin{array}{l}\text { Women who consider there to be no level of alcohol consumption } \\
\text { that is safe for pregnancy }{ }^{1}\end{array}$ & 116 & 98.3 & 48 & 98.0 & 68 & 98.6 & 1 \\
\hline $\begin{array}{l}\text { Women who consider there to be no level of tobacco consumption } \\
\text { that is safe for pregnancy }{ }^{3}\end{array}$ & 104 & 90.4 & 42 & 91.3 & 62 & 89.9 & 1 \\
\hline \multicolumn{8}{|l|}{$\begin{array}{l}\text { Actions considered by women to guaranty a healthy pregnancy } \\
\text { with no notion of ranking }\end{array}$} \\
\hline To reduce or stop alcohol consumption & 87 & 71.9 & 30 & 57.7 & 57 & 82.6 & 0.002 \\
\hline To cut down on or stop smoking & 86 & 71.1 & 32 & 61.5 & 54 & 78.3 & 0.04 \\
\hline
\end{tabular}

${ }^{1}$ Three missing values (three subjects with a level 0 to 4 of qualification); ${ }^{2}$ four missing values (four subjects with a level 0 to 4 of qualification); ${ }^{3}$ six missing values (six subjects with a level 0 to 4 of qualification). ${ }^{*}$ Chi-squared test or Fisher's exact test.

Table 5. Behavioral changes concerning alcohol and tobacco consumption during pregnancy $(n=121)$.

\begin{tabular}{|c|c|c|c|c|c|c|c|}
\hline & \multicolumn{2}{|c|}{$\begin{array}{c}\text { Total } \\
(n=121)\end{array}$} & \multicolumn{2}{|c|}{$\begin{array}{l}\text { Level } 0 \text { to } 4 \text { of } \\
\text { Qualification } \\
\quad(n=52)\end{array}$} & \multicolumn{2}{|c|}{$\begin{array}{c}\text { Level } 4 \text { to } 8 \\
\text { Qualification } \\
(n=69)\end{array}$} & \multirow[t]{2}{*}{$p$-Value * } \\
\hline & $n$ & $\%$ & $n$ & $\%$ & $n$ & $\%$ & \\
\hline Smoking status before knowledge of pregnancy ${ }^{1}$ & & & & & & & 0.003 \\
\hline Non-smoker & 98 & 82.4 & 35 & 70.0 & 63 & 91.3 & \\
\hline Smoker & 21 & 17.6 & 15 & 30.0 & 6 & 8.7 & \\
\hline $\begin{array}{l}\text { Daily consumption of cigarettes among smokers before knowledge } \\
\text { of pregnancy }\end{array}$ & & & & & & & 0.44 \\
\hline$[1-10]$ & 5 & 23.8 & 3 & 20.0 & 2 & 33.3 & \\
\hline [10-20] & 11 & 52.4 & 7 & 46.7 & 4 & 66.7 & \\
\hline$\geq 20$ & 5 & 23.8 & 5 & 33.3 & 0 & 0.0 & \\
\hline Behavioral changes during pregnancy among smokers & & & & & & & 0.15 \\
\hline Stopped smoking during pregnancy & 8 & 38.1 & 4 & 26.7 & 4 & 66.7 & \\
\hline Cut down on smoking during pregnancy & 13 & 61.9 & 11 & 73.3 & 2 & 33.3 & \\
\hline Daily consumption of cigarettes among smokers during pregnancy & & & & & & & 0.58 \\
\hline [1-5] & 4 & 30.8 & 4 & 36.4 & 0 & 0 & \\
\hline$[5-10]$ & 8 & 61.5 & 6 & 54.5 & 2 & 100 & \\
\hline [10-15] & 1 & 7.7 & 1 & 9.1 & 0 & 0 & \\
\hline Daily number of alcohol units consumed before pregnancy ${ }^{2}$ & & & & & & & 0.75 \\
\hline 0 & 106 & 90.6 & 47 & 92.2 & 59 & 89.4 & \\
\hline 1 & 11 & 9.4 & 4 & 7.8 & 7 & 10.6 & \\
\hline Daily number of alcohol units during pregnancy ${ }^{3}$ & & & & & & & 1 \\
\hline 0 & 118 & 100 & 51 & 100 & 67 & 100 & \\
\hline
\end{tabular}

Changes in consumption habits among women are presented Figure 4. Subjects who did not ordinarily use the mentioned products were removed from the results. 


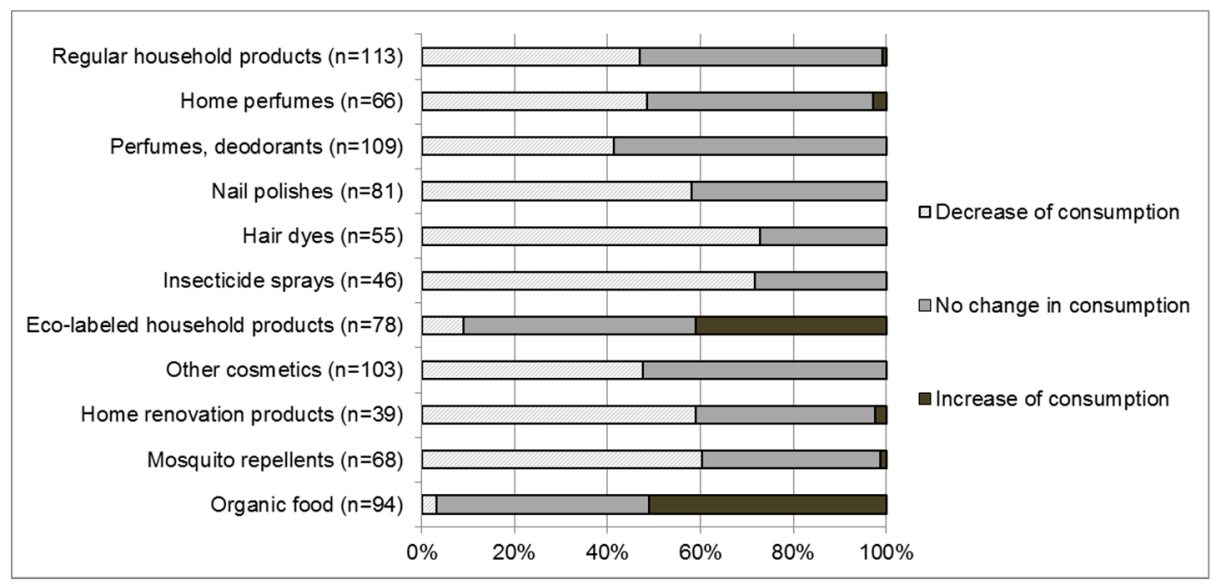

Figure 4. Change in consumption habits among women who use a range of common products $(n=121)$.

In our study population, $81 \%$ of women $(n=98)$ implemented at least one action among the 11 items proposed in the survey to reduce exposure to chemicals present in daily products. The median number of actions undertaken by the subjects was 3.5. More than the half the users reduced their consumption of hair dyes $(73 \%)$, insecticide sprays $(72 \%)$, mosquito repellent $(60 \%)$, and home renovation products $(59 \%)$. There were several differences concerning the actions implemented by women that approached the significance threshold, according to their level of education. Women with a higher level of education were more inclined to increase their consumption of organic food $(p=0.06)$ and decrease their use of hair dyes $(p$ value $=0.05)$ and nail polish $(p=0.08)$. There was no statistical difference between these results depending on the number of pregnancies.

\subsection{Source of Information about the Environment}

Table 6 presents the frequency of women who considered they were sufficiently informed about the environment and subjects' sources of information. Results have been ranked by priority order.

Table 6. Women's sources of information about the environment $(n=121)$.

\begin{tabular}{|c|c|c|}
\hline & \multicolumn{2}{|c|}{ Total } \\
\hline & $n(n=121)$ & $\%$ \\
\hline \multicolumn{3}{|l|}{$\begin{array}{l}\text { Women who considered that they were sufficiently informed about the } \\
\text { environment }{ }^{1}\end{array}$} \\
\hline No/Do not know & 82 & 70.1 \\
\hline Yes & 35 & 29.9 \\
\hline $\begin{array}{l}\text { Women who have been informed about the environment during } \\
\text { pregnancy by physicians }\end{array}$ & 54 & 44.6 \\
\hline \multicolumn{3}{|l|}{ Principal sources of information } \\
\hline Internet & 100 & 82.6 \\
\hline Television & 69 & 57.0 \\
\hline Midwife & 52 & 43.0 \\
\hline Magazines & 48 & 39.7 \\
\hline Entourage & 44 & 36.4 \\
\hline Gynecologist & 44 & 36.4 \\
\hline Maternity & 30 & 24.8 \\
\hline General practitioner & 30 & 24.8 \\
\hline \multicolumn{3}{|l|}{ Relevant sources of information identified by women } \\
\hline Midwives & 99 & 81.8 \\
\hline Gynecologists and obstetricians & 88 & 72.7 \\
\hline General practitioner & 45 & 37.2 \\
\hline Occupational physician & 11 & 9.1 \\
\hline Other: Primary Sickness Insurance Fund & 2 & 1.7 \\
\hline
\end{tabular}

${ }^{1}$ Four missing values. 
Internet and television were the first sources reported by $83 \%$ and $57 \%$ of women, respectively, whereas health practitioners were less frequently mentioned. Women indicated having more often been informed about the environment by midwives during their pregnancy than by other health professionals. Only $45 \%$ of the subjects $(n=54)$ were informed about environmental risks by a physician.

However, $82 \%$ of women $(n=68)$ considered that they were not sufficiently informed about environmental risks. They identified midwives, gynecologists, and obstetricians among the best professionals to advise them about environmental risks to pregnancy. Only $9 \%$ of women $(n=11)$ identified the occupational physician as a relevant source of information.

\section{Discussion}

The main objective of our study was to evaluate the perception of women concerning the occupational and non-occupational environment and assess their behavioral changes during pregnancy.

Most (91\%) women identified the environment as a major determinant of health during pregnancy. Although the risks concerning tobacco and alcohol consumption were well-known, the level of knowledge concerning other harmful substances was incomplete. Nevertheless, most women implemented preventive measures in both their occupational and non-occupational environment during pregnancy. At the workplace, most of such changes were made without the assistance of the employer or the occupational health physician. At home, most women implemented at least one action to diminish their exposure to chemical products.

\subsection{Perceptions of Environmental Risks and Behavioral Changes at Work}

In our study, a large proportion of women (71\%) implemented preventive measures by themselves, suggesting they were aware of the role of the environment during pregnancy. Fewer women $(40 \%)$ benefited from preventive measures implemented by the employer. Nevertheless, we observed no statistical difference in the accommodations made between women considered to be exposed and those considered to be unexposed. This raises concerns about the relevance and adequacy of the adaptations implemented.

According to the French Labor Code [23], the occupational physician is the key actor to assess risks at the workstation and propose appropriate accommodations, if needed. Based on our results, changes at the workstation were made without any contact with an occupational physician, as only $10 \%$ of the respondent women consulted with this practitioner during their pregnancy. These results can be explained by the absence of automatic notification by the employer to the occupational physician about the worker's pregnancy, combined with the lack of early declaration. Indeed, $91 \%$ of women were aware of their pregnancy during the first month. However, they frequently delayed their declaration of the pregnancy to the employer until after the first trimester, even though this period corresponds to organogenesis, which is a window of high vulnerability during fetal development [24]. The workers' lack of knowledge about the role of this practitioner could also explain the low frequency of consultations since only $9 \%$ of the subjects identified the occupational physician as a relevant source of information. Finally, several other barriers to effective prevention of pregnant and breastfeeding workers have been reported, such as the difficulty to identify substances that are dangerous for reproduction, the lack of updated criteria, guidance, and legislation on chemicals, and the lack of coordination among gynecologists and occupational physicians [25].

\subsection{Knowledge and Behavior Concerning Alcohol and Tobacco}

Our study showed that tobacco and alcohol are the best-known risk factors for pregnancy. These results are consistent with those of other studies that have been conducted in several other countries $[15,26]$.

No women declared to have consumed alcohol daily during their pregnancy. The design of our survey did not permit us to record infrequent alcohol consumption. Among the respondents, 
$11 \%$ of women smoked during their pregnancy, but at lower levels than before. Despite the use of an anonymous survey, we cannot exclude that women underestimated their consumption of toxic substances (prevarication bias).

The proportion of tobacco and alcohol consumers in our population was lower than that revealed by another French study [16]. This can be explained by the higher proportion of women with a higher level of education in our population, as this parameter is associated with economic status, which has been identified as an important factor for substance use during pregnancy in the scientific literature [27].

Our study did not assess the possible reasons to explain the observed knowledge-behavior gap. Indeed, we observed that a good knowledge of potential risks was not sufficient to motivate women to stop smoking, in accordance with other studies [28]. Several quantitative studies have identified a number of barriers to smoking cessation among pregnant women, including willpower, the role and meaning of smoking, issues with the provision of smoking cessation aids, changes in relationship interactions, understanding of the facts, changes in smell and taste, and the influence of family and friends [28].

\subsection{Knowledge and Behavior Concerning the Daily Use of Products}

Almost all of the respondents declared to have implemented behavioral changes in their household habits. Most of the difference in knowledge and behavior among women were explained by the level of education and age. These results are consistent with those of another French qualitative study showing that these two parameters influence the perception of the risk due to endocrine disruptors in a population of pregnant women [17].

Household income may also explain some changes made in daily life, such as the increase in the consumption of organic foods and eco-labelled products. Indeed, in a French survey conducted by the Ministry in charge of the Environment, the respondents reported price as an important element in determining their consumption of labeled products, even if their perception of these products had improved over the past years [29].

\subsection{Source of Information about the Environment}

In our study, $70 \%$ of women considered that they were not sufficiently informed about environmental risks. Their major sources of information were the popular media (internet, television, and magazines), for which the quality of the information provided is highly variable. Few pregnant women were counselled about the environment by health providers. Several studies have shown that perinatal health providers do not generally ask patients about their environmental exposure, except for the consumption of toxic substances [30,31]. An American survey found that less than $20 \%$ of obstetricians routinely interview their patients about their environment [32]. The difficulties most frequently cited were the lack of training and knowledge in environmental health, the lack of evidence-based information, the short duration of consultations [30-33], the fear of patient reactions, and the lack of solutions [33].

Our results suggest that counselling by health professionals could be the most effective way to inform and encourage women to adopt appropriate behaviors during pregnancy. Respondents identified midwives, gynecologists, and obstetricians as the best sources of information. There is a true need to remove the barriers noted by physicians.

\subsection{Strengths and Weaknesses of the Study}

A strength of our study was the large scope of risk factors examined, notably harmful chemical substances that are rarely investigated in the scientific literature [15]. Moreover, we were able to simultaneously assess knowledge and behavioral changes, to identify potential gaps, and occupational and non-occupational environments, which are too often separated in medical approaches, preventing 
the establishment of global and effective preventive measures. Participation in the study was high $(80 \%)$, suggesting a strong interest of the participants in this topic.

The characteristics of our study population were close to those of the French population of postpartum women in 2016 [34]. Overall, our results are largely consistent with the findings of other French studies, as already discussed [16-18].

A major limitation of our study was the exclusion of women who had adverse pregnancy outcomes or women with language barriers or reading difficulties. It is possible that this population may have been more exposed to environmental risk factors during pregnancy. The level of knowledge and the proportion of behavioral changes may be lower than among the women included in our study. Consequently, we cannot extrapolate our results to this specific population and dedicated studies should be conducted.

However, these results provide new information and contribute towards a better understanding of the perception and behavior of women concerning environmental risks for further reflection about the preventive measures that could be improved or implemented in occupational and household environments.

\section{Conclusions}

Women in this study perceive the environment as a strong factor that influences the proper course of pregnancy. Accordingly, a majority initiated behavioral changes during their pregnancy at work and/or in their private life. However, such corrective measures are rarely implemented in consultation with health practitioners, such as the occupational physician at the workplace or a perinatal practitioner in the non-occupational environment. Most of the information received by women comes from non-scientifically validated sources, such as the internet, television, and magazines. There is a true need to reduce the barriers identified in several studies to include the environment as a systematic component of pregnancy management, as suggested by the International Federation of Gynecology and Obstetrics [11].

Author Contributions: L.S. and F.D. contributed to the study conception. R.T. developed the survey, contributed to the analysis, and wrote the article. M.L. administered the survey and contributed to the analysis. J.C. and G.M. contributed to the analysis. All authors have read and approved the final article before submission.

Funding: This research did not receive external funding.

Acknowledgments: We thank all the perinatal health professionals of the Department of Obstetrics and Gynecology who helped with the administration and collection of the survey.

Conflicts of Interest: The authors declare they have no actual or potential competing financial interest.

\section{References}

1. Scott-Goodwin, A.C.; Puerto, M.; Moreno, I. Toxic effects of prenatal exposure to alcohol, tobacco and other drugs. Reprod. Toxicol. 2016, 61, 120-130. [CrossRef] [PubMed]

2. Vrijheid, M.; Casas, M.; Gascon, M.; Valvi, D.; Nieuwenhuijsen, M. Environmental pollutants and child health-A review of recent concerns. Int. J. Hyg. Environ. Health 2016, 219, 331-342. [CrossRef] [PubMed]

3. Slama, R.; Cordier, S. Impact of chemical and physical environmental factors on the course and outcome of pregnancy. J. Gynecol. Obstet. Biol. Reprod. (Paris) 2013, 42, 413-444. [CrossRef]

4. Hanke, W.; Jurewicz, J. The risk of adverse reproductive and developmental disorders due to occupational pesticide exposure: an overview of current epidemiological evidence. Int. J. Occup. Med. Environ. Health 2004, 17, 223-243.

5. Jørgensen, K.T.; Jensen, M.S.; Toft, G.V.; Larsen, A.D.; Bonde, J.P.; Hougaard, K.S. Risk of cryptorchidism among sons of horticultural workers and farmers in Denmark. Scand. J. Work. Environ. Health 2014, 40, 323-330. [CrossRef] [PubMed]

6. Quansah, R.; Jaakkola, J.J. Occupational exposures and adverse pregnancy outcomes among nurses: A systematic review and meta-analysis. J. Womens Health 2010, 19, 1851-1862. [CrossRef] [PubMed] 
7. Lawson, C.C.; Rocheleau, C.M.; Whelan, E.A.; Lividoti Hibert, E.N.; Grajewski, B.; Spiegelman, D.; Rich-Edwards, J.W. Occupational exposures among nurses and risk of spontaneous abortion. Am. J. Obstet. Gynecol. 2012, 206, 327.e1-327.e8. [CrossRef] [PubMed]

8. Ronda, E.; Moen, B.E.; García, A.M.; Sánchez-Paya, J.; Baste, V. Pregnancy outcomes in female hairdressers. Int. Arch. Occup. Environ. Health 2010, 83, 945-951. [CrossRef]

9. Henrotin, J.-B.; Picot, C.; Bouslama, M.; Collot-Fertey, D.; Radauceanu, A.; Labro, M.; Larroque, B.; Roudot, A.-C.; Sater, N.; Elhkim, M.O.; et al. Reproductive disorders in hairdressers and cosmetologists: A meta-analytical approach. J. Occup. Health 2015, 57, 485-496. [CrossRef]

10. Halliday-Bell, J.A.; Gissler, M.; Jaakkola, J.J.K. Work as a hairdresser and cosmetologist and adverse pregnancy outcomes. Occup. Med. Oxf. Engl. 2009, 59, 180-184. [CrossRef]

11. Di Renzo, G.C.; Conry, J.A.; Blake, J.; DeFrancesco, M.S.; DeNicola, N.; Martin, J.N.; McCue, K.A.; Richmond, D.; Shah, A.; Sutton, P.; et al. International Federation of Gynecology and Obstetrics opinion on reproductive health impacts of exposure to toxic environmental chemicals. Int. J. Gynaecol. Obstet. Off. Organ Int. Fed. Gynaecol. Obstet. 2015, 131, 219-225. [CrossRef] [PubMed]

12. Hemsing, N.; Greaves, L.; Poole, N. Preconception health care interventions: A scoping review. Sex. Reprod. Healthc. 2017, 14, 24-32. [CrossRef] [PubMed]

13. Thompson, E.L.; Vázquez-Otero, C.; Vamos, C.A.; Marhefka, S.L.; Kline, N.S.; Daley, E.M. Rethinking Preconception Care: A Critical, Women's Health Perspective. Matern. Child Health J. 2017, 21, 1147-1155. [CrossRef] [PubMed]

14. Addati, L.; Cassirer, N.; Gilchrist, K. Maternity and Paternity at Work-Law and Practice across the World; International Labour Office: Geneva, Switzerland, 2014.

15. Toivonen, K.I.; Oinonen, K.A.; Duchene, K.M. Preconception health behaviours: A scoping review. Prev. Med. 2017, 96, 1-15. [CrossRef] [PubMed]

16. Chabert, M.-C.; Perrin, J.; Berbis, J.; Bretelle, F.; Adnot, S.; Courbiere, B. Lack of information received by a French female cohort regarding prevention against exposure to reprotoxic agents during pregnancy. Eur. J. Obstet. Gynecol. Reprod. Biol. 2016, 205, 15-20. [CrossRef] [PubMed]

17. Rouillon, S.; Deshayes-Morgand, C.; Enjalbert, L.; Rabouan, S.; Hardouin, J.-B.; Group DisProSE; Migeot, V.; Albouy-Llaty, M. Endocrine Disruptors and Pregnancy: Knowledge, Attitudes and Prevention Behaviors of French Women. Int. J. Environ. Res. Public Health 2017, 14, 1021. [CrossRef] [PubMed]

18. Henrotin, J.-B.; Vaissière, M.; Etaix, M.; Dziurla, M.; Malard, S.; Lafon, D. Occupational risks during pregnancy: Feedback from occupational medical services. Gynecol. Obstet. Fertil. Senol. 2018, 46, $20-27$.

19. Dean, A.; Arner, T.; Sunki, G.; Friedman, R.; Lantinga, M.; Sangam, S.; Zubieta, J.; Sullivan, K.; Brendel, K.; Gao, Z.; et al. Epi Info ${ }^{T M}$, a Database and Statistics Program for Public Health Professionals; CDC: Atlanta, GA, USA, 2011. Available online: https:/ / wwwn.cdc.gov/ (accessed on 11 February 2019).

20. UNESCO Institute for Statistics International Standard Classification of Education ISCED 2011. Available online: http://uis.unesco.org/sites/default/files/documents/international-standard-classification-ofeducation-isced-2011-en.pdf (accessed on 11 February 2019).

21. Teysseire, R.; Brochard, P.; Sentilhes, L.; Delva, F. Identification and Prioritization of Environmental Reproductive Hazards: A First Step in Establishing Environmental Perinatal Care. Int. J. Environ. Res. Public Health 2019, 16. [CrossRef]

22. International Labour Organization International Standard Classification of Occupations Structure, Group Definitions and Correspondence Tables 2012. Available online: https://www.ilo.org/public/english/ bureau/stat/isco/docs/groupdefn08.pdf (accessed on 11 February 2019).

23. Shettle, J. Pregancy, Maternity and Work—Legal Aide-Memoire 2018. Available online: http:/ / www.inrs.fr/ dms/inrs/CataloguePapier/ED/TI-TJ-14/tj14.pdf (accessed on 11 February 2019).

24. Barouki, R.; Gluckman, P.D.; Grandjean, P.; Hanson, M.; Heindel, J.J. Developmental origins of non-communicable disease: implications for research and public health. Environ. Health Glob. Access Sci. Source 2012, 11, 42. [CrossRef]

25. Romano, D.; Moreno, N. Barriers for the prevention of chemical exposures in pregnant and breast-feeding workers? J. Epidemiol. Community Health 2010, 64, 193. [CrossRef]

26. Frey, K.A.; Files, J.A. Preconception Healthcare: What Women Know and Believe. Matern. Child Health J. 2006, 10, 73-77. [CrossRef] [PubMed] 
27. Lamy, S.; Thibaut, F. Psychoactive substance use during pregnancy: A review. L'Encephale 2010, 36, 33-38. [CrossRef] [PubMed]

28. Ingall, G.; Cropley, M. Exploring the barriers of quitting smoking during pregnancy: a systematic review of qualitative studies. Women Birth J. Aust. Coll. Midwives 2010, 23, 45-52. [CrossRef] [PubMed]

29. General Commission for Sustainable Development. French Lifestyles and Environmental Practices; General Commission for Sustainable Development: New York, NY, USA, 2018; p. 100.

30. Massaquoi, L.D.; Edwards, N.C. A Scoping Review of Maternal and Child Health Clinicians Attitudes, Beliefs, Practice, Training and Perceived Self-Competence in Environmental Health. Int. J. Environ. Res. Public Health 2015, 12, 15769-15781. [CrossRef] [PubMed]

31. Marie, C.; Lémery, D.; Vendittelli, F.; Sauvant-Rochat, M.-P. Perception of Environmental Risks and Health Promotion Attitudes of French Perinatal Health Professionals. Int. J. Environ. Res. Public Health 2016, 13, 1255. [CrossRef] [PubMed]

32. Stotland, N.E.; Sutton, P.; Trowbridge, J.; Atchley, D.S.; Conry, J.; Trasande, L.; Gerbert, B.; Charlesworth, A.; Woodruff, T.J. Counseling patients on preventing prenatal environmental exposures-A mixed-methods study of obstetricians. PLoS ONE 2014, 9, e98771. [CrossRef] [PubMed]

33. Sunyach, C.; Antonelli, B.; Tardieu, S.; Marcot, M.; Perrin, J.; Bretelle, F. Environmental Health in Perinatal and Early Childhood: Awareness, Representation, Knowledge and Practice of Southern France Perinatal Health Professionals. Int. J. Environ. Res. Public Health 2018, 15, 2259. [CrossRef]

34. Blondel, B.; Coulm, B.; Bonnet, C.; Goffinet, F.; Le Ray, C. Trends in perinatal health in metropolitan France from 1995 to 2016: Results from the French National Perinatal Surveys. J. Gynecol. Obstet. Hum. Reprod. 2017, 46, 701-713. [CrossRef]

(C) 2019 by the authors. Licensee MDPI, Basel, Switzerland. This article is an open access article distributed under the terms and conditions of the Creative Commons Attribution (CC BY) license (http:/ / creativecommons.org/licenses/by/4.0/). 